Environment Conservation Journal 14(3) 101-104, 2013

ISSN 0972-3099 (Print) 2278-5124 (Online)

Abstracted and Indexed

\title{
Phytochemical screening and evaluation of Berginia ligulata root extract for antimicrobial activity
}

\author{
Rishi Kumar Shukla
}

Received: 22.09.2013

Revised: 28.10 .2013

Accepted: 22.11.2013

\begin{abstract}
Berginia ligulata popularly known as paashaanbhed belongs to family Saxifragaceae. The present study was designed to screen out various phytoconstituents present in the roots of Berginia ligulata and further its antimicrobial activity against human pathogenic bacteria. For this roots of the plant were shade dried, powdered and extracted using different solvents in increasing order of polarity i.e. petroleum ether, diethyl ether, acetone, ethanol and methanol respectively. Preliminary phytochemical screening of the extracts revealed the presence of steroids, terpenoids, alkaloids, tannins, flavanoids, glycosides and carbohydrates. The presence of these bioactive constituents is associated with the antimicrobial activity of the plant. Antimicrobial activity of extracts was performed by disc diffusion method at a concentration of $100 \%$ and $50 \%$ (w/v) against five bacterial strains. The maximum antimicrobial activity was found in ethanol extract followed by acetone, methanol, diethyl ether and least in petroleum ether extract respectively. Ethanol extract revealed broad spectrum of inhibition against $S$. sureus and $P$. aeruginosa.
\end{abstract}

Keyword: Berginia ligulata, paashaanbhed, antimicrobial activity, phytochemical screening

\section{Introduction}

Though the traditional Indian system of medicine has a long history of use, they lacked adequate scientific documentation, particularly in light modern scientific knowledge (WHO, 1998). Bergenia ligulata Wall. (Syn. Saxifraga ligulata), family Saxifragaceae, is a perennial herb with thick rootstock, short stem, white, pink or purple flowers and found in South and East Asia. In India, it grows at high altitudes in the Himalayas usually in rocky areas and in the Kashmir valley where it is popularly known as Paashaanbhed. It is found in the Himalayas between the altitudes of 2,000 and 2,500 meters. The roots contain tannic acid, gallic acid, starch, mineral salt, albumin, glucose, mucilaginous matter, wax and aromatic substances. The roots are used as an antidiabetic, diuretic, astringent, cardiotonic, wound healer, expectorant, anti-haemorrhoidal, tonic in fever, diarrhea and also as an antiscorbutic. (Kritikar and Basu, 1983 \& Gyanendra, 1988). Chemical investigations have shown the presence of $\beta$-sitosterol, $\beta$-sitosterol-Dglucoside, bergenin (Bahl et al., 1974) and

\section{Author's Address}

Department of Chemistry, Gurukul Kangri Vishwavidyalaya, Haridwar, India

Email: rks.hdr@gmail.com paashaanolactone (Umashankar et al., 1998). Bergenin and $\beta$-sitosterol are well known for pharmacological actions. This plant is explored a very little for pharmacological activity. Thus we have studied this plant for its antimicrobial activity so that its traditional use can be claimed. The present study explores the preliminary phytochemical and anti-microbial screening of roots of Berginia ligulata and establishes a correlation between the phytoconstituents and their antimicrobial activity.

\section{Material and methods \\ Plant material}

Fresh roots of Bergenia ligulata were collected from Aushdhiya vanaspati van sansthan, Dehradun, Uttarakhand and authentication was done by Dr. Santosh Kumar Agarwal (Head Department of Botany, D.B.S. (P.G.) College Dehradun. The roots were shade dried, grind into powder and stored in polythene bags before use.

\section{Extraction of plant material}

$104.367 \mathrm{~g}$ of powdered roots of Bergenia ligulata was extracted in a soxhlet extractor sequentially with $700 \mathrm{ml}$ of petroleum ether $\left(40-60^{\circ} \mathrm{C}\right)$, diethyl ether, acetone, ethanol and methanol in increasing 
order of polarity. The obtained extracts were concentrated at reduced pressure in a rotary vacuum evaporator.

\section{Preliminary phytochemical investigation}

The major secondary metabolites like, alkaloids, flavonoids, saponins, phenols, terpenoids, anthraquinones, carbohydrates and glycosides were assessed according to the standard procedure described by Harborne (Harborne, 1984).

\section{Microorganism used}

A total of five out of which four gram negative and one gram positive human pathogenic bacterial strains were used in the present study. The bacterial species used were Escherichia coli, Staphylococcus aureus, Klebsiella pneumonia, Pseudomonas aeruginosa and Enterobacter

\section{Culture media and inoculum}

Muller Hinton Agar and Nutrient broth (Hi-Media Pvt. Ltd., Bombay, India) were used as culture for the test microorganism. Microbial cultures, freshly grown at $37^{\circ} \mathrm{C}$ were appropriately diluted in sterile normal saline solution and the turbidity of the suspension is adjusted equivalent to a 0.5 McFarland standard, so as to obtain the cell suspension between $10^{5}$ to $10^{8} \mathrm{CFU} / \mathrm{ml}$ (McFarland, 1907).

\section{Preparation of test extract}

Solvent free extracts obtained were dissolved in sterilized and filtered DMSO (filtered with whatman filter of pore size 0.45 micron) to prepare a test solution of extract of $50 \%$ and $100 \%(\mathrm{w} / \mathrm{v})$ concentration.

\section{Antimicrobial Activity}

The antimicrobial activity of the extracts was performed by standard protocol of Kirby- Bauer disc diffusion susceptibility method (Bauer et al., 1966). In this method, $6 \mathrm{~mm}$ sterilized filter paper discs were saturated with sterilized extracts of the test solution. The discs absorb approximately a 10 $\mu \mathrm{l}$ of the test solution. The discs were stored and dried in the cold. The seeded discs are then placed on to the surface of MHA pre-inoculated with test bacteria. The disc devoid of extract and presence of DMSO served as control. Ofloxacin $(5 \mu \mathrm{g} / \mathrm{disc})$ and Ciprofloxacin $(10 \mu \mathrm{g} / \mathrm{disc})$ were used as standard. The plates were kept at $4{ }^{0} \mathrm{C}$ for 1 hour for diffusion of extract, thereafter the plates were incubated at $37{ }^{\circ} \mathrm{C}$ for 24 hours. After incubation, zone of inhibition was measured in $\mathrm{mm}$ (millimeter). All the test processes were performed in a triplicate in laminar chamber.

\section{Results and Discussion \\ Extractive Yield}

The extractive yield (w/w) of Berginia ligulata root extracts is shown in Table 1. The yield was maximum in ethanol extract (10.124) followed by acetone (4.591), methanol (3.778), diethyl ether (1.184) and least in petroleum ether (0.777) extract respectively.

\section{Preliminary phytochemical investigation}

The result of phytochemical screening (Table 2) revealed that Berginia ligulata root contain a number of secondary metabolites like alkaloids, carbohydrates, glycosides, steroids, terpenoids, tannin, flavonoid and saponnin. Ethanol and acetone extract contains majority of phytoconstituents in comparison to others,

\section{Table 1:- Extractive yield of different extracts of Berginai ligulata root extract}

\begin{tabular}{lccc}
\hline Extracts & Appearance & Consistency & \% Yield (w/w) \\
\hline Petroleum ether & Pale yellow & Fluidy and sticky & 0.777 \\
Diethyl ether & Pale brown & Waxy & 1.184 \\
Acetone & Dark Brown & Semisolid & 4.591 \\
Ethanol & Dark Brown & Semisolid & 10.124 \\
Methanol & Brown & Semisolid & 3.778 \\
\hline
\end{tabular}


extractive yield is also suggestive for it. The presence of various phytoconstituents implies that the roots of this plant might be of medicinal importance to pharmaceutical industries as the phytoconstituents of the plants account for their medicinal value.
Antimicrobial Activity

All the extracts screened, showed significant reduction in bacterial growth in terms of zone of inhibition, indicating that this plant exhibits antimicrobial activity against the microorganisms; the zone of inhibition was recorded and tabulated (Table 3).

Table 2:- Phytochemical evaluation of Berginia ligulata root extract

\begin{tabular}{lccccc}
\hline \multirow{2}{*}{ Phytoconstituents } & \multicolumn{5}{c}{ Extracts } \\
\cline { 2 - 5 } & Petroleum ether & Diethyl ether & Acetone & Ethanol & Methanol \\
\hline Steroid & + & + & + & + & - \\
Terpenoid & + & + & + & - & - \\
Alkaloid & + & + & + & + & - \\
Tannin & - & - & + & + & - \\
Flavonoid & - & - & + & + & + \\
Glycoside & - & - & + & + & + \\
Saponnin & - & - & - & + & + \\
Carbohydrate & - & - & - & + \\
\hline
\end{tabular}

Table 3:- Antimicrobial activity of Berginia ligulata root extracts compared with standard drug Ofloxacin and Ciprofloxacin

\begin{tabular}{|c|c|c|c|c|c|c|c|c|}
\hline \multirow{2}{*}{$\begin{array}{l}\text { Bacterial } \\
\text { strain } \\
\text { (Gram stain) }\end{array}$} & \multirow{2}{*}{$\begin{array}{l}\text { Conc } \\
\% \\
(w / v)\end{array}$} & \multicolumn{4}{|c|}{ Zone of Inhibition in $\mathrm{mm}^{*}$} & \multirow[b]{2}{*}{ Methanol } & \multirow[b]{2}{*}{$\begin{array}{l}\text { Ofloxacin } \\
(5 \mu \mathrm{g} / \text { disc })\end{array}$} & \multirow[b]{2}{*}{$\begin{array}{l}\text { Ciprofloxacir } \\
(10 \mu \mathrm{g} / \text { disc })\end{array}$} \\
\hline & & $\begin{array}{l}\text { Petroleum } \\
\text { Ether }\end{array}$ & Diethyl ether & Acetone & Ethanol & & & \\
\hline \multirow{2}{*}{$\begin{array}{l}\text { S. aureus } \\
(+)\end{array}$} & 100 & $14.100 \pm 1.65$ & $14.980 \pm 2.30$ & $17.565 \pm 2.08$ & $21.350 \pm 2.96$ & $14.960 \pm 1.70$ & \multirow{2}{*}{$24.330 \pm 2.08$} & \multirow{2}{*}{$28.600 \pm 0.78$} \\
\hline & 50 & $12.000 \pm 0.78$ & $13.125 \pm 1.25$ & $14.563 \pm 1.10$ & $16.250 \pm 1.59$ & $13.990 \pm 1.78$ & & \\
\hline \multirow{2}{*}{$\begin{array}{l}\text { E. coli } \\
(-)\end{array}$} & 100 & $10.220 \pm 0.65$ & $12.330 \pm 0.56$ & $13.660 \pm 1.52$ & $15.657 \pm 1.05$ & $12.085 \pm 1.15$ & \multirow{2}{*}{$21.200 \pm 1.17$} & \multirow{2}{*}{$28.000 \pm 0.50$} \\
\hline & 50 & $8.020 \pm 0.25$ & $11.580 \pm 1.32$ & $11.220 \pm 1.46$ & $13.120 \pm 2.08$ & $10.090 \pm 1.90$ & & \\
\hline \multirow{2}{*}{$\begin{array}{l}\text { K. } \\
\text { pneumonia } \\
(-)\end{array}$} & 100 & $12.010 \pm 1.32$ & $14.211 \pm 1.86$ & $14.325 \pm 4.16$ & $16.694 \pm 1.68$ & $14.969 \pm 2.33$ & \multirow{2}{*}{$20.000 \pm 1.36$} & \multirow{2}{*}{$30.100 \pm 1.89$} \\
\hline & 50 & $11.500 \pm 0.36$ & $12.860 \pm 0.92$ & $13.462 \pm 2.19$ & $14.085 \pm 0.98$ & $12.450 \pm 2.98$ & & \\
\hline \multirow{2}{*}{$\begin{array}{l}\text { P. aeruginosa } \\
(-)\end{array}$} & 100 & $13.060 \pm 1.87$ & $15.830 \pm 0.85$ & $17.238 \pm 0.57$ & $20.696 \pm 2.50$ & $16.086 \pm 1.05$ & \multirow{2}{*}{$16.500 \pm 1.15$} & \multirow{2}{*}{$36.20 \pm 1.10$} \\
\hline & 50 & $11.500 \pm 1.23$ & $13.056 \pm 1.12$ & $15.055 \pm 1.85$ & $18.114 \pm 2.12$ & $13.600 \pm 1.45$ & & \\
\hline \multirow{2}{*}{$\begin{array}{l}\text { Enterobacter } \\
(-)\end{array}$} & 100 & $13.660 \pm 2.08$ & $13.000 \pm 2.64$ & $15.000 \pm 2.08$ & $18.326 \pm 1.52$ & $13.262 \pm 1.52$ & \multirow{2}{*}{$19.500 \pm 1.73$} & \multirow{2}{*}{$24.000 \pm 0.79$} \\
\hline & 50 & $11.850 \pm 1.42$ & $10.400 \pm 3.69$ & $13.850 \pm 1.14$ & $14.780 \pm 2.17$ & $11.476 \pm 2.40$ & & \\
\hline
\end{tabular}

(-): No zone of inhibition, *Results are expressed as mean of 3 values \pm s.d. 
The extracts seem to be active against gram positive and gram negative bacteria. Ethanol extract shows maximum potential of inhibition against all bacterial strains followed by acetone and methanol extract. Maximum inhibition (21.350) was shown by $S$. aureus against ethanol extract. For $P$. aeruginosa ethanol extract is even inhibitorier at both concentrations when compared with standard ofloxacin. Similarly the zone of inhibition of ofloxacin and ethanol extract is nearly equal for Enterobacter. The standard ciprofloxacin reveals much larger inhibition zone than ofloxacin and extracts against all the strains. Generally, the use of synthetic antibiotics gives a more potent antimicrobial activity when compared to a crude extract. But one thing that always should be remembered that synthetic antimicrobial have undesirable side effects as compared to the natural antimicrobials of plant origin (Iwu et al., 1999). The antimicrobial activity of extracts is possibly due to the presence of various phytoconstituents, however the tremendous activity of ethanol extract perhaps due to the presence of majority of these phytoconstituents in that single extract.

So the above study clearly illustrates the pharmacological use of Berginia ligulata roots as antimicrobial agents, due to which it can be used for preparing in formulation of various pharmaceutical preparations against highly expensive synthetic antimicrobial agent. Further its traditional use as antimicrobial agent is also well demonstrated by this study.

\section{References}

Bahl, C.P., Murari, R., Parthasarathy, M.R., Seshadri, T.R., 1974. Indian Journal of Chemistry. 12: 1038-1039.

Baur, A.W., Kirby, W.M.M., Sherris, J.C., Turch, M., 1966. Antibiotic susceptibility testing by a standardized single disc method. American Journal of Clinical Pathology, 45:494-496.

Gyanendra, P., 1988. Dravyaguna Vijnana, Krishanadas Academy, Varanasi, India. 3: 69-71.

Harborne, J.B., 1984. A Guide to Modern techniques of Plant Analysis. Chapman and Hall, London, pp. 4-80.

Iwu, M.M., Duncan, A.R., Okunji, C.O., 1999. New Antimicrobials of Plant Origin. In: Janick J, editor. Perspectives on new crops and new uses. Alexandria: ASHS Press, 459.

Kirtikar, K.R., Basu, B.D. 1983. Indian Medicinal Plants, International Book Distributors, Dehradun, India. 3: 993994.

McFarland, J. 1907. The nephelometer: an instrument for estimating the numbers of bacteria in suspensions used for calculating the opsonic index and for vaccines. The Journal of the American Medical Association. 49, 11761178

Umashankar, D.C., Amric, S.C., Deepak, M., Rakesh, M., Sukhdev, S.H., 1998. Paashaanolactone from Bergenia ligulata. Phytochemistry. 47: 907-909.

World Health Organization (WHO) 1998. Quality Control Methods for Medicinal Plant Materials, WHO, Geneva,. 